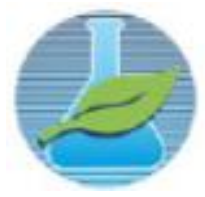

Vol. 02 N. 04 (2016) 043-045
JCEC/REQ ${ }^{2}$

Journal

ISSN: 2446-9416

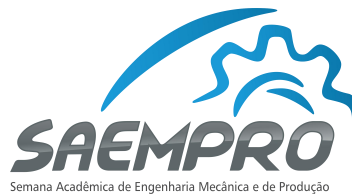

\author{
"EU, A INDÚSTRIA E O MUNDO" \\ 08 a 11 de novembro de 2016 no campus Vicosa da UFV \\ Departamento de Engenharia de Produção e Mecânica - DEP \\ Universidade Federal de Viçosa - UFV
}

\title{
SELEÇÃO DE HÉLICES PARA O MOTOR O.S.0.61FX COM MELHOR DESEMPENHO EM DECOLAGEM
}

\author{
Kalleb Morais de Moura Abreu \\ Universidade Federal de Viçosa, Departamento de Engenharia de Produção e Mecânica \\ Ph. Rolfs s/n - 36570-000 - Viçosa - MG \\ kalleb.abreu@ufv.br
}

\section{INTRODUÇÃO}

A Equipe Skywards de Aerodesign tem como objetivo participar da Competição SAE BRASIL $A E R O D E S I G N$ 2016. Para isso, é preciso que a equipe construa um avião rádio controlado que carregue o maior peso possível e que respeite as distâncias de pouso e decolagem impostas pelo regulamento.

Para Rodrigues (2014), a hélice representa um elemento de grande importância num avião. Ela tem a missão de fornecer a força de tração necessária ao voo. Em termos simples, uma hélice é um aerofólio trabalhando em uma trajetória circular, com ângulo de ataque positivo em relação ao fluxo de ar, de forma a produzir tração em uma direção paralela ao plano de voo da aeronave.

Logo, a escolha do grupo motor propulsor (hélice e motor) que garanta a menor distância de decolagem é fundamental para o projeto. O objetivo deste resumo é apresentar a metodologia utilizada, pela Equipe Skywards de Aerodesign em 2016, para a seleção da hélice com melhor desempenho em decolagem para o motor O.S.0.61FX.

\section{METODOLOGIA}

A metodologia consiste em analisar o comportamento do conjunto motor propulsor em função da velocidade do ar. Para isso, utilizou-se uma bancada com célula de carga e sensores de velocidade, força, temperatura, pressão e densidade do ar conectados a um arduíno, além do motor O.S.0.61FX e hélices tais como: 13x4w APC C2 Nylon, 13x4 APC C2 Nylon, 13x4 Madeira, 12x8 APC C2 Nylon, 12x6 APC C2 Nylon. Para a variação da velocidade do vento a bancada foi apoiada na janela de um carro que era acelerado em uma pista reta. A Figura 1 ilustra a montagem descrita.

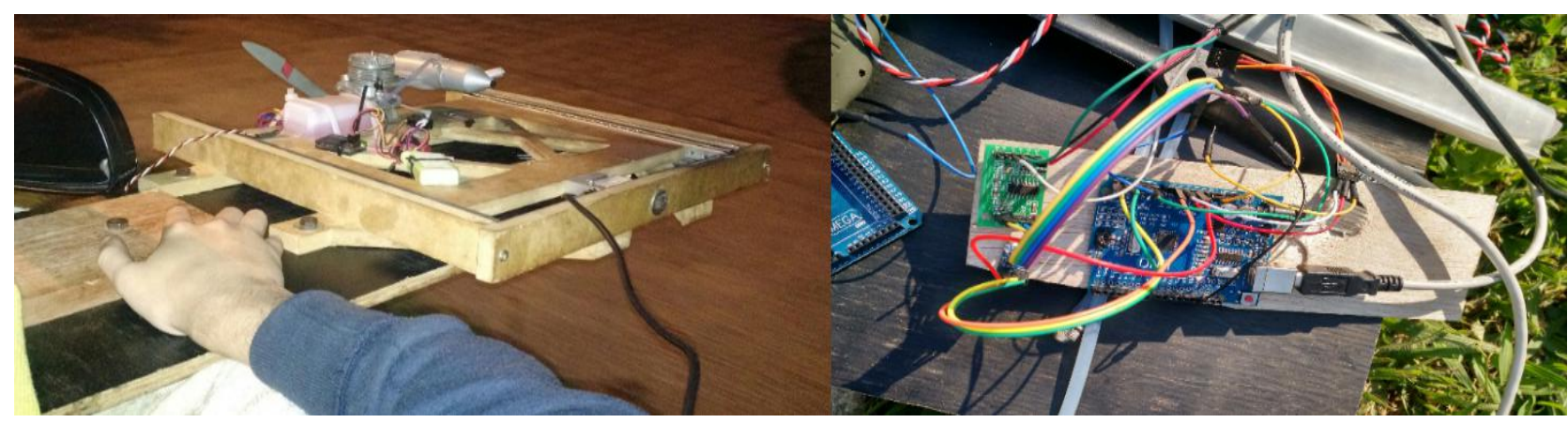

Figura 1 - Esquerda: bancada posicionada no carro, direita: sistema de sensores do arduíno (Fonte própria). 


\section{RESULTADOS}

Com os valores obtidos pelo teste foi possível determinar, através da ferramenta Curve Fitting do software MatLab ${ }^{\circledR}$, as curvas de tendência. Utilizou-se o método polinômio de segunda ordem. Com todas as curvas de tração disponível determinadas, criou-se o gráfico da Fig. 2. Como o objetivo do projeto é carregar a maior carga paga possível dentro do limite de pista estipulado é fundamental garantir a maior tração disponível durante a decolagem. Observou-se que a hélice 13x4w APC C2 Nylon obteve maior tração disponível durante toda a faixa de velocidade e por isso foi escolhida. Logo, o grupo motor propulsor da equipe é composto pelo motor O.S.0.61FX e hélice $13 \times 4 \mathrm{w}$ APC C2 Nylon.

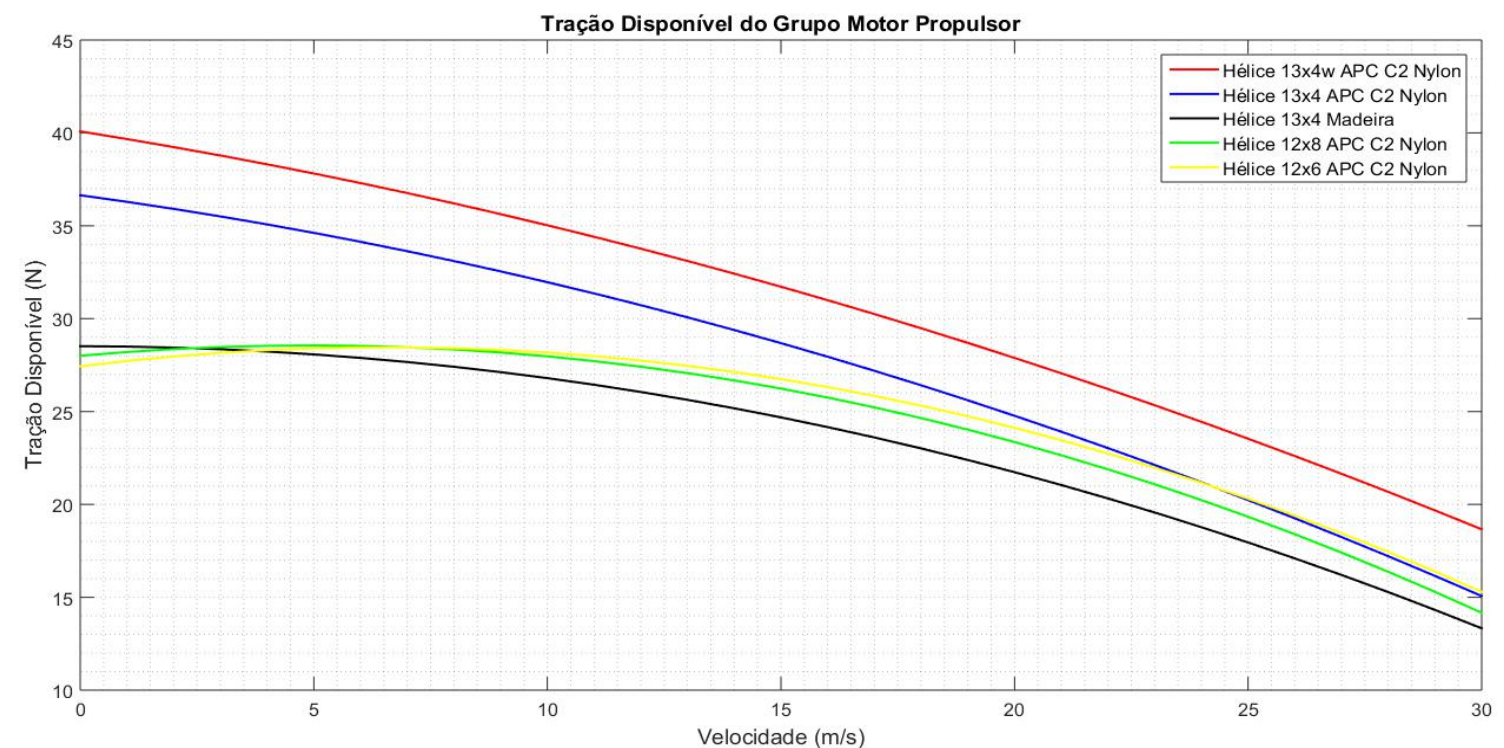

Figura 2 - Tração disponível para as hélices selecionadas para o teste (Fonte própria).

Com o grupo motor propulsor definido, construiu-se o gráfico do comprimento de pista em função do peso, representado pela Fig. 3. Com a finalidade de garantir uma margem de segurança quanto a distância de decolagem máxima permitida $(60 \mathrm{~m})$ a equipe optou por aceitar como válido apenas o projeto que respeitasse a restrição de decolagem a uma altitude de $1500 \mathrm{~m}$, superior à da cidade de São José dos Campos, local onde ocorrerá a competição.

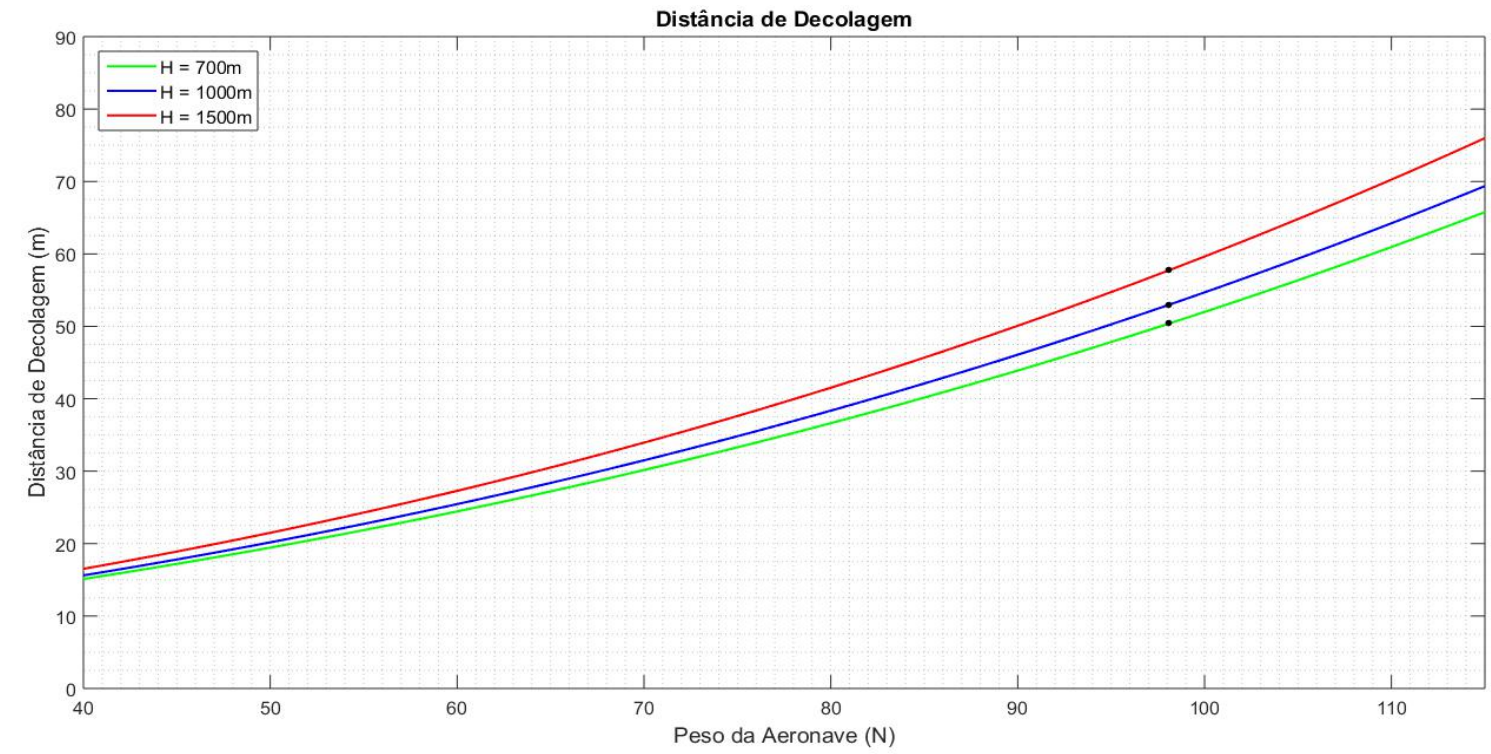

Figura 3 - Gráfico de distância de decolagem em função do peso da aeronave (Fonte própria). 


\section{CONSIDERAÇÕES FINAIS}

Em virtude dos dados encontrados determinou-se que a hélice 13x4w APC C2 Nylon apresenta um melhor desempenho em conjunto com o motor O.S.0.61FX. A hélice mencionada acima teve desempenho superior em todo o envelope de voo e foi capaz de garantir uma distância menor do que os 60 m determinados segundo o regulamento da Competição SAE BRASIL AERODESIGN 2016.

\section{AGRADECIMENTOS}

Agradecemos o apoio da FAPEMIG por meio do Programa Santos Dumont no apoio ao desenvolvimento do projeto e a FUNARBE.

\section{REFERÊNCIAS}

ANDERSON, J. D. “Aircraft performance and design”. New York: McGraw-Hill Education, 1998. RODRIGUES, L. E. M. J. "Fundamentos da engenharia aeronáutica com aplicações ao Projeto SAE-Aerodesign: aerodinâmica e desempenho". Salto: www.engbrasil.eng.br, 2014. 